University of Wollongong

Research Online

Faculty of Engineering and Information

Faculty of Engineering and Information

Sciences - Papers: Part B

Sciences

2020

Group self-build housing: A bottom-up approach to environmentally and socially sustainable housing

Emma Elizabeth Heffernan

University of Wollongong, eheffern@uow.edu.au

Pieter De Wilde

Plymouth University

Follow this and additional works at: https://ro.uow.edu.au/eispapers1

Part of the Engineering Commons, and the Science and Technology Studies Commons

Research Online is the open access institutional repository for the University of Wollongong. For further information contact the UOW Library: research-pubs@uow.edu.au 


\title{
Group self-build housing: A bottom-up approach to environmentally and socially sustainable housing
}

\author{
Abstract \\ In England, there is a longstanding and increasing undersupply of both affordable and open-market \\ housing. Around three quarters of all new homes in the UK are currently built speculatively by the \\ developer-led private housing sector. However, demand for self-build housing is growing. Concurrently, \\ there is also a need to address the sustainability of homes, which represent $29 \%$ of final energy \\ consumption in the UK. There is a clear imperative to develop business models within the construction \\ sector in which both social and environmental sustainability are inherent. The aim of this paper is to \\ explore professional and expert opinions on the suitability of group self-build housing as a development \\ model for zero carbon homes. A Policy Delphi study was conducted both at a national level in England \\ and at a regional level in South West England. In this iterative, non-contact research method, online \\ questionnaires were used to gather data from the same panellists over three rounds. Panellists were \\ drawn from seven groups: public sector, specialist groups/experts, housing associations, housing \\ developers, designers, contractors, and financial institutions. The findings highlight that the panellists \\ believe that group self-build is well suited as a development model for the delivery of zero carbon homes \\ and sustainable communities. The advantages identified include: energy efficiency, affordability, quality, \\ innovation, and sustainable communities.

\section{Disciplines \\ Engineering | Science and Technology Studies}

\section{Publication Details} \\ Heffernan, E. \& De Wilde, P. (2020). Group self-build housing: A bottom-up approach to environmentally \\ and socially sustainable housing. Journal of Cleaner Production, 243 118657-1-118657-11.
}


Group self-build housing: A bottom-up approach to environmentally and socially sustainable housing

Dr Emma Heffernan ${ }^{* a}$ and Prof Pieter de Wilde ${ }^{b}$

a School of Civil, Mining and Environmental Engineering, University of Wollongong, NSW 2522, Australia. eheffern@uow.edu.au

b School of Architecture Design and Environment, Plymouth University, Drake Circus, Plymouth, PL4 8AA, UK. pieter.dewilde@plymouth.ac.uk

*corresponding author

To cite this work:

Heffernan, E. and de Wilde, P. (2020) 'Group self-build housing: A bottom-up approach to environmentally and socially sustainable housing', J ournal of Cleaner Production, vol. 243.

https:// doi.org/ 10.1016/j.jclepro.2019.118657

(c) 2019. This manuscript version is made available under the CC-BY-NC-ND 4.0 license http:// creativecommons.org/licenses/ by-nc-nd/4.0/ 


\begin{abstract}
In England, there is a longstanding and increasing undersupply of both affordable and openmarket housing. Around three quarters of all new homes in the UK are currently built speculatively by the developer-led private housing sector. However, demand for self-build housing is growing. Concurrently, there is also a need to address the sustainability of homes, which represent $29 \%$ of final energy consumption in the UK. There is a clear imperative to develop business models within the construction sector in which both social and environmental sustainability are inherent. The aim of this paper is to explore professional and expert opinions on the suitability of group self-build housing as a development model for zero carbon homes. A Policy Delphi study was conducted both at a national level in England and at a regional level in South West England. In this iterative, non-contact research method, online questionnaires were used to gather data from the same panellists over three rounds. Panellists were drawn from seven groups: public sector, specialist groups/ experts, housing associations, housing developers, designers, contractors, and financial institutions. The findings highlight that the panellists believe that group self-build is well suited as a development model for the delivery of zero carbon homes and sustainable communities. The advantages identified include: energy efficiency, affordability, quality, innovation, and sustainable communities.
\end{abstract}

Keywords: Policy Delphi, group self-build, zero carbon, sustainable, housing 


\section{Introduction}

In 2004, the Review of Housing Supply (Barker, 2004) identified a need to significantly increase the number of new homes built in the UK in order to both address unmet demand for more homes, and stabilise the volatile housing market. This shortfall in housing supply has continued since the Barker Review (2004), and an undersupply in affordable housing has also been identified (J efferys et al., 2014; Wilson and Barton, 2018). Whilst demand for self-build housing is believed to be growing (Wilson, 2017), a significant majority of new homes in the UK are currently built speculatively by the developer-led private housing sector. Alongside unmet demand in housing quantity, the UK Government has a legally binding target of reducing carbon dioxide $\left(\mathrm{CO}_{2}\right)$ emissions by $80 \%$ of 1990 levels by 2050 (HM Government, 2008). In 2018, the domestic sector accounted for approximately $29 \%$ of final energy consumption in the UK (Department for Business Energy \& Industrial Strategy, 2019). There is therefore a growing imperative to address the environmental sustainability of new homes.

The literature asserts that self-build homes are more likely to be environmentally sustainable than homes built by speculative housebuilders (Brown et al., 2013; DCLG, 2011; Falk and Carley, 2012; Parvin et al., 2011) and that group self-build is more likely to create sustainable communities, than developments procured by speculative housing developers (Boonstra and Boelens, 2011; Brown et al., 2013; Wallace et al., 2013). Previous research identified the need to encourage more self-build methods of procurement, as a long-term solution to the low uptake of environmentally sustainable construction practices in the UK housing sector (Heffernan et al., 2015). There is therefore a necessity to develop business models within the construction sector in which both social and environmental sustainability are inherent, and self-build may provide one such solution. Consequently, the aim of this paper is to explore professional and expert opinions on the suitability of group self-build housing as a development model for zero carbon homes and sustainable communities.

The remainder of this paper is organised as follows: Section 2 provides definitions for and an overview of the literature relating to self-build housing and zero carbon homes. Section 3 presents the research design, and Section 4 provides the results from the Policy Delphi study. Section 5 discusses the research findings before a conclusion and implications for policy and practice are presented in Section 6.

\section{Self-build housing and zero carbon homes}

The housebuilding sector in the UK broadly comprises three types of housing, as categorised by developer: speculative housing, not-for-profit/limited profit housing, and selfbuild/custom build housing (Barlow et al., 2001). Speculative housing is developed by a private developer, and then sold on the open market. Throughout the design and construction 
processes, the final purchaser is typically unknown to the developer (Parvin et al., 2011). The speculative developer's short-term relationship with the homes they produce influences design and specification decisions, often resulting in poor quality homes (Palmer, 2019). Notfor-profit or limited-profit housing is typically developed by Housing Associations or Local Authorities. Affordable housing is allocated for either rental or intermediate housing (e.g. shared ownership) based on an assessment of need. Self-build housing is any form of housing where the first occupants of a new home are involved in its production, either by arranging for its construction or being involved in building it themselves to some degree (Barlow et al., 2001). In the UK, a self-builder is required to build in accordance with the Building Regulations (HM Government, 2010), but no pre-qualification of skills and abilities is required. Estimates on the proportion of UK homes delivered through self-build vary from $8 \%$ (Barlow et al., 2001; Wallace et al., 2013) to 10\% (DCLG, 2011). However, accurate statistics on the level of self-build activity in the UK are not available, as no official data on procurement route are collected.

Following the global financial crisis which took hold from 2008, with continuing concerns regarding the over reliance on the volume housebuilding sector to build homes, the UK Government sought to diversify the delivery of housing through the encouragement of more resilient sources of supply (DCLG, 2011), one element of which has been a focus on self-build housing. To this end, the UK Government expressed an aspiration to double the size of the UK self-build housing sector over the decade to 2020. The Housing Strategy (DCLG, 2011) states that 'custom [self-build] housing can make a stronger contribution to economic growth. By making it easier for ordinary peopleto build their own homes, there is the potential to deliver wider benefits of affordable, greener and innovatively designed homes' (DCLG, 2011, p. 14). The UK Government has since reaffirmed this commitment (DCLG, 2017) and has provided policy support for the self-build housing sector (Wilson, 2017). Notwithstanding the lack of official data, recent modest increases in self-build activity have been reported (Wilson, 2017).

Within the literature, different terminologies are used when discussing self-build housing. Benson (2014) suggests that 'self-build' is often used as an 'umbrella term' to incorporate the multiple routes to self-build. Duncan and Rowe (1993) introduced the term 'self-provided' as an alternative to self-build, to encompass both those who undertake the labour themselves and those who employ a contractor to do so, this terminology was also adopted by Parvin et al. (2011). In the Housing Strategy (DCLG, 2011) the term 'custom build' was introduced to replace the term 'self-build'. The National Custom and Self Build Association (NaCSBA) (2018) makes a distinction between the two terms, defining self-build involving a developer as custom build. 
The emphasis within this paper is on forms of self-build procurement involving a group of homes (three or more) rather than individual homes. In the context of non-speculative group housing developments, there is a similar, or possibly even greater, diversity of both models and terminologies. Benson (2014) and Tummers (2016) highlight a lack of conceptual clarity because of this diversity and lack of consensus in terminology and definition. Commonly adopted terminologies include: self-managed housing, intentional communities, and cohousing (Tummers, 2016); collaborative, co-operative, self-built and self-organised housing (Palmer, 2019); eco-developments and community land trusts (Wallace et al., 2013); collective custom build (Brown et al., 2013); and the German Baugruppen (group-build) (Hamiduddin and Gallent, 2016). NaCSBA (2018) define three routes to group self-build: independent community collaboration, supported community self-build group, and developer-led group project. These routes provide a useful way of categorising based on the formation or organisation of groups, although different models may overlap or function in multiple route categories. Whilst reviewing the diverse terminology in this field is not the intention within this paper, as this has been undertaken by others (Palmer, 2019), it is relevant for the purposes of contextualising group self-building, to present here the routes to group self-build, some of the related models/ terminology, and example projects (see Table 1).

Table 1: Routes to group self-build, common models and example projects

\begin{tabular}{|c|c|c|c|}
\hline $\begin{array}{l}\text { Route to group } \\
\text { self-build }\end{array}$ & Common models & Example projects & $\begin{array}{l}\text { Reference for } \\
\text { example project }\end{array}$ \\
\hline \multirow{3}{*}{$\begin{array}{l}\text { Independent } \\
\text { community } \\
\text { collaboration }\end{array}$} & $\begin{array}{l}\text { Eco-village, } \\
\text { Co-operative }\end{array}$ & $\begin{array}{l}\text { Narara Ecovillage, NSW, } \\
\text { Australia }\end{array}$ & (Narara Ecovillage, 2019) \\
\hline & $\begin{array}{l}\text { Ecological } \\
\text { affordable } \\
\text { cohousing }\end{array}$ & LILAC, Leeds, UK & (Chatterton, 2013) \\
\hline & $\begin{array}{l}\text { Baugruppen } \\
\text { (group-build) }\end{array}$ & $\begin{array}{l}\text { Sülzer Freunde, Cologne, } \\
\text { Germany }\end{array}$ & $\begin{array}{l}\text { (Hamiduddin and Gallent, } \\
\text { 2016) }\end{array}$ \\
\hline \multirow{3}{*}{$\begin{array}{l}\text { Supported } \\
\text { community self- } \\
\text { build group }\end{array}$} & $\begin{array}{l}\text { Community Land } \\
\text { Trust }\end{array}$ & $\begin{array}{l}\text { Easterways, } \\
\text { Broadhempston, UK }\end{array}$ & $\begin{array}{l}\text { (Broadhempston } \\
\text { Community Land Trust, } \\
\text { n.d.) }\end{array}$ \\
\hline & $\begin{array}{l}\text { Sweat equity } \\
\text { project }\end{array}$ & $\begin{array}{l}\text { Habitat for Humanity } \\
\text { project, Peckham, UK }\end{array}$ & (Wheat, 2001) \\
\hline & Self-build for rent & Hedgehog, Brighton, UK & (Wheat, 2001) \\
\hline \multirow{2}{*}{$\begin{array}{l}\text { Developer-led } \\
\text { group project }\end{array}$} & Custom build & $\begin{array}{l}\text { HomeMade, Heartlands, } \\
\text { Cornwall, UK }\end{array}$ & (PfP igloo, n.d.) \\
\hline & Cohousing & $\begin{array}{l}\text { Marmalade Lane, } \\
\text { Cambridge, UK }\end{array}$ & (Trivselhus, 2019) \\
\hline
\end{tabular}


Whilst research focusing on self-build housing in the UK has increased in recent years, group self-build has tended to comprise only a small element in these studies (e.g. Benson, 2014; Wallace et al., 2013). There have been far fewer studies with an explicit focus on group selfbuild (e.g. Brown et al., 2013; Collins, 2017; Heffernan and deWilde, 2017), hence theinterest in focusing on the group scale within this research. Further reasons for the group focus include the government sector support for group self-build (Aspinall Verdi, 2016), and the potential for group scale benefits. Group self-build enables projects of a similar scale to speculative housing projects (e.g. LILAC(Chatterton, 2013) and HomeMade, Heartlands (PfP igloo, n.d.)), but at present group self-build is believed to be responsible for a very small proportion of new homes built in the UK.

In 2007, the UK Government formally announced its intention for a mandatory zero carbon homes standard for all new homes from 2016 (DCLG, 2007). When it was announced, it was stated that a zero carbon home would have zero 'net carbon emissions from all energy used in the home' over a year (DCLG, 2007, p. 5). The proposed standard went through a number of iterations, before being abandoned by government in 2015 (Greenwood et al., 2017). When data collection for the research presented in this paper was undertaken, the introduction of the zero carbon homes standard was fast approaching, and the challenge set by the proposed standard had been significantly reduced in magnitude. The zero carbon homes standard is conceptualised as a policy aspiration for environmental sustainability in housing (with a distinct focus on carbon emissions reduction). The contemporary proposed definition was adopted in this research, and provided a common understanding for the research participants. The zero carbon homes standard comprised three elements for compliance: a Fabric Energy Efficiency Standard (FEES), on-site energy generation using low or zero carbon technologies (Carbon Compliance), and local carbon off-setting (Allowable Solutions) (Zero Carbon Hub, 2014). In its final iteration, the proposed definition was no longer aligned with the energy/ carbon standard for Level 6 of the Code for Sustainable Homes, as it had been when first promoted (DCLG, 2007), instead, the on-site energy requirements had been reduced to between those for Levels 4 and 5 of the Code (Heffernan et al., 2015). Despite the standard having now been abandoned, it remains relevant as an aspirational exemplar of environmental sustainability policy for housing. Indeed, Lovell and Corbett (2018) highlight that zero carbon homes were being built in the UK before the standard was introduced, and continue to be built after its abolition.

Whilst the literature cites that self-build homes typically feature enhanced energy efficiency (Brown et al., 2013; Parvin et al., 2011) and superior performance in use (Miles and Whitehouse, 2013), Marckmann et al. (2012) found that the environmental consequences of the size of self-build homes was notably absent in self-builders' discussions, despite the floor 
area of a home representing a significant factor in its overall energy consumption (GramHanssen, 2011). Furthermore, individual self-build homes are often large detached dwellings, in low density developments, which potentially has a negative impact in the broader sense of sustainability (Dol et al., 2012). Tummers (2016) suggests models of group self-build are appropriate for brownfield sites as a form of sustainable urban development. Consideration of the broader nature and scale of developments is therefore important. Because the act of building in a group engenders a sense of community (Broer and Titheridge, 2010; Falk and Carley, 2012), it has been suggested that group self-build is more likely to create sustainable communities than developments procured by speculative housing developers (Boonstra and Boelens, 2011; Brown et al., 2013; Wallace et al., 2013). Benson and Hamiduddin (2017) highlight the social significance of self-build, which they characterise as a social process, even more so at group scale. It is therefore of interest to consider whether the group self-build housing sector could provide an appropriate vehicle for the delivery of zero carbon homes and sustainable communities.

\section{Methods}

A Policy Delphi study was conducted to explore expert opinions at a national level in England and with a regional focus in South West England. The South West, comprising the counties of Bristol, Cornwall, Devon, Dorset, Gloucestershire, Somerset, Wiltshire and the Isles of Scilly, was selected as a regional focus due to growing demand for and decreasing supply of new homes in the region (HBF, 2012). It has been suggested that volume housebuilders do not favour the South West due to the small and often complex nature of sites in the region, and the remoteness from their well-established supply chains (Heffernan, 2015). It is believed that group self-build is more predominant in the region than other areas of England. Indeed, there has been a relative abundance of community-led housing delivery in the South West, in the form of, inter alia, cohousing (e.g. Springhill Cohousing, 2017) and numerous community land trusts (National Community Land Trust Network, 2019).

The Policy Delphi method is a non-contact, iterative, group research process in which data is collected from the same research participants in a number of successive rounds. Group research processes have been stated to be superior to non-group research processes (e.g. de Loe, 1995; Landeta and Barrutia, 2011) because they are likely to identify a greater number of unique ideas of a higher quality. However, as a result of the direct contact made between participants, group processes, such as focus groups, can be subject to disadvantages (Turoff, 2002) including: potential dominance of individuals, unwillingness to state an opinion until the position of the majority is known, and reticence to change an opinion once stated. The benefits that the Delphi method offers include that it provides all participants with an opportunity to give their opinion, it can stop participants feeling compelled to conform to the 
opinion of others, and it offers participants the opportunity to carefully consider their responses (de Loe 1995). Through its quasi-anonymity, participants are also provided the opportunity to contradict individuals in senior positions (Turoff, 2002).

Policy Delphi has previously been used to study a broad range of subject areas including: education (Landeta and Barrutia, 2011; Wright, 2006), tourism (Paraskevas and Saunders, 2012), health (O’Loughlin and Kelly, 2004; Picavet et al., 2012), and sustainable business (Fernández-Viñé et al., 2013). Policy Delphi is most appropriate where the research interest lies in revealing all the opinions, options, and advantages and disadvantages in relation to a specific policy issue, and the reasoning behind them. Therefore, with the aim of exploring the opinions of experts and professionals on the suitability of group self-build housing as a development model for zero carbon homes and sustainable communities, these concepts sitting firmly within the sphere of policy in the built environment, Policy Delphi was seen as an appropriate method to employ.

Policy Delphi employs a heterogeneous sample group. Participants are expected to have knowledge and experience in the subject area, possibly with an expertise in one aspect of it, but are not expected to be knowledgeable about all aspects of an issue. Maximum variation sampling (Tracy, 2013), a form of purposive sampling in which participants are selected based on their value to the research (Rubin and Rubin, 2005), was used to ensure the heterogeneity of the sample group. In Policy Delphi studies, it is important for the researcher to establish criteria for the selection of participants (Keeney et al., 2006). The sample group for this study comprised construction professionals and experts in self-build housing. Potential participants were identified through self-build networks (e.g. NaCSBA (NaCSBA, 2019)), case study projects, and academic publications. Participants needed to satisfy at least one of the following criteria in order to be selected to participate: 1) knowledge of group self-build, 2) a keen interest in group self-build, or 3) to have had experience of group-self-build. The regional study recruited a panel of participants working primarily in South West England, whereas the national study recruited a panel of participants from across England. To include representatives from the multiple professional groups which havethe potential to interact with self-builders, participants from the following categories were invited for both panels: public sector, self-build housing specialists, housing associations, housing developers, designers, contractors, and financial institutions.

The originator of the Policy Delphi methodology suggested that a panel should comprise between 10 and 50 participants (Turoff, 2002). However, Rayens and Hahn (2000) suggest that a typical Policy Delphi will recruit 10 to 30 participants. Within this study, with the aim of achieving a sample size of approximately 30 participants, and based on anticipated levels of recruitment and retention between the Delphi rounds (Landeta and Barrutia, 2011), 73 and 70 
potential participants were invited respectively for the regional and national studies. Three rounds of online questionnaire survey were conducted using the online survey platform 'Qualtrics' (Qualtrics, 2019).

In the Round 1 questionnaire, participants were asked the open-ended question What are the advantages and disadvantages of self-build housing as a development model for zero carbon homes?'. Due to the iterative nature of the Policy Delphi method, it was necessary to analyse the data from the previous round in order to develop the questionnaire for the next round. Thematic analysis (Bailey et al., 2012; Creswell, 2014) of the responses to the open-ended questions was conducted using NVivo (QSR International, 2019). A series of statements was developed for the Round 2 questionnaire survey, based on the findings from Round 1. For each statement, the participants were asked to indicate their level of agreement using a six-point Likert scale, to force respondents to express an opinion, based upon their professional knowledge (Hahn and Rayens, 1999). Using open-ended questions, panellists were also asked for the reasoning for their responses. The questionnaire survey for Round 3 sought to review the responses to some of the questions with the lowest level of consensus from the previous round.

\subsection{Data Analysis}

Taking the stance that Likert scale data is not interval data (Cohen et al., 2011), all data from Likert scale statements within this study are treated as ordinal data. The mode is therefore used when reporting descriptively on the data as a 'measure of central tendency' (Clegg, 1997). The percentage of positive responses (strongly agree, agree and somewhat agree) is also presented. A modified version of de Loe's (1995) consensus definition is presented and employed (Table 2).

\section{Table 2: Criteria for levels of consensus}

\begin{tabular}{ll}
\hline Consensus level & Criteria \\
\hline High & $60 \%$ in one agreement category or \\
& $70 \%$ in two contiguous categories to one side of the central position or \\
& $80 \%$ in three contiguous categories to one side of the central position \\
& $50 \%$ in one agreement category or \\
& $60 \%$ in two contiguous categories to one side of the central position or \\
Medium & $70 \%$ in three contiguous categories to one side of the central position \\
& $40 \%$ in one agreement category or \\
& $50 \%$ in two contiguous categories to one side of the central position or \\
& $60 \%$ in three contiguous categories to one side of the central position \\
& $<60 \%$ in three contiguous categories to one side of the central position \\
\hline
\end{tabular}




\section{Findings}

\subsection{Panellist categorisation}

The number of participants/ panellists for each round of both thenational and regional studies are presented in Tables 3 and 4 respectively. Within the regional study, there was an absence of panellists from the contractor group in all rounds and housing developers were only represented in Round 1. This is due to invited participants being either unable or unwilling to take part. The financial institution category was also unrepresented in the regional study, due to there being no specialist financial institutions involved in group self-build located within the South West.

Table 3: Regional study - Panellists categorised

\begin{tabular}{lrrr}
\hline Category & Round 1 & Round 2 & Round 3 \\
\hline Public sector & 15 & 13 & 8 \\
Specialist groups/ experts & 7 & 6 & 5 \\
Housing associations & 4 & 3 & 2 \\
Housing developers & 1 & - & - \\
Designers & 3 & 3 & 2 \\
Contractors & - & - & - \\
Financial institutions & - & - & - \\
\hline Totals & $\mathbf{3 0}$ & $\mathbf{2 5}$ & $\mathbf{1 7}$ \\
\hline Invited & 73 & 30 & 25 \\
\hline Response rate & $\mathbf{4 1 \%}$ & $\mathbf{8 3 \%}$ & $\mathbf{6 8 \%}$ \\
\hline
\end{tabular}

Table 4: National study - Panellists categorised

\begin{tabular}{lrrr}
\hline Category & Round 1 & Round 2 & Round 3 \\
\hline Public sector & 2 & - & - \\
Specialist groups/ experts & 9 & 8 & 7 \\
Housing associations & 2 & 2 & 2 \\
Housing developers & 3 & 2 & 2 \\
Designers & 4 & 2 & 1 \\
Contractors & 2 & 2 & 2 \\
Financial institutions & 1 & 1 & 1 \\
\hline Totals & $\mathbf{2 3}$ & $\mathbf{1 7}$ & $\mathbf{1 5}$ \\
\hline Invited & 70 & 23 & 17 \\
\hline Response rate & $\mathbf{3 3 \%}$ & $\mathbf{7 4 \%}$ & $\mathbf{8 8 \%}$ \\
\hline
\end{tabular}


4.2 Advantages of group self-build as a development model for zero carbon homes In Round 1, panellists were asked to identify the advantages of group self-building as a development model for zero carbon homes. From the responses, six themes were identified (Table 5). Energy efficiency and sustainable communities were the themes identified most often by the panellists.

Table 5: Advantages of group self-build as a development model for zero carbon homes

\begin{tabular}{|c|c|}
\hline Theme & Specific advantages \\
\hline Energy efficiency & $\begin{array}{l}\text { Better understanding of the home energy system } \\
\text { Ability to specify higher standards of energy efficiency } \\
\text { Sharing information and awareness about zero carbon } \\
\text { Lifestyle choice } \\
\text { Shared energy systems } \\
\text { Stimulate demand for zero carbon/ energy efficient homes } \\
\text { Lower cost frees up funding for additional measures } \\
\text { Willingness to explore lower impact materials and methods }\end{array}$ \\
\hline Affordability & $\begin{array}{l}\text { Economies of scale in construction } \\
\text { Access to funding/ finance available only to the group self- } \\
\text { build sector } \\
\text { Lower running costs } \\
\text { Sweat equity } \\
\text { Capacity to 'spend to save' }\end{array}$ \\
\hline Quality & Self-builders have a vested interest in quality \\
\hline Innovation & $\begin{array}{l}\text { Prepared to take risks with unproven technologies } \\
\text { Self-builders are keen/ happy to innovate } \\
\text { Self-build inspires innovation and creativity }\end{array}$ \\
\hline Sustainable communities & $\begin{array}{l}\text { The act of building as a group builds community bonds } \\
\text { Homes for local people } \\
\text { Resilient, less transient community } \\
\text { Supports (adaptation to) sustainable lifestyle (e.g. Car } \\
\text { sharing, food growing) } \\
\text { Shared energy systems } \\
\text { Variety - more interesting urban design } \\
\text { Empowering } \\
\text { Builds skills and confidence } \\
\text { Supporting local businesses }\end{array}$ \\
\hline Meeting the needs of occupants & $\begin{array}{l}\text { Ability to procure a tailored design } \\
\text { Increased satisfaction } \\
\text { Greater input into specification and materials } \\
\text { Flexibility of supply chain }\end{array}$ \\
\hline
\end{tabular}

Statements were developed from each of the themes identified in response to the Round 1 questionnaire. Panellists indicated their level of agreement using a six-point Likert scale. Table 6 shows the response counts in relation to the advantages of group self-build in the regional 
study. Respondents are in a high level of agreement with every statement except 'Group selfbuild or custom build has no advantages'. The statement with the highest level of consensus and agreement across both studies is 'Group self-build or custom build is more likely to meet the needs of the occupants'.

Respondents in thenational study did not identify the theme 'Group self-build or custom build has no advantages', this question was not therefore asked. However, the remainder of the questions were the same (Table 7). The most notable difference between the results of the regional and the national studies is in relation to the statement 'Group self-build or custom build is more likely to be energy efficient'. In the regional study, all of the respondents were in some level of agreement with the statement, whereas in the national study this was not the case for two respondents. However, for both studies, the mode response was 'agree' and the consensus level was high.

Table 6: Regional study - Round 2 - Advantages of group self-build

\begin{tabular}{|c|c|c|c|c|c|c|c|c|}
\hline $\begin{array}{l}\text { Group self-build or custom build } \\
\text { (is more likely to)... }\end{array}$ & 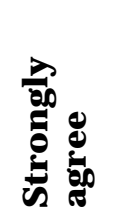 & 离 & 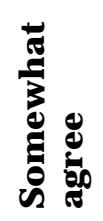 & 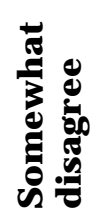 & 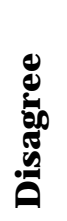 & 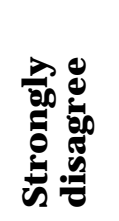 & 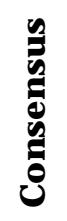 & 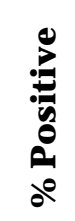 \\
\hline be energy efficient & 3 & 14 & 6 & - & - & - & $\mathrm{H}$ & 100 \\
\hline be affordable & 1 & 9 & 10 & 1 & 2 & - & $\mathrm{H}$ & 87 \\
\hline be innovative & 3 & 13 & 6 & - & 1 & - & $\mathrm{H}$ & 96 \\
\hline be of a higher quality & 3 & 7 & 11 & 2 & - & - & $\mathrm{H}$ & 91 \\
\hline meet the needs of the occupants & 9 & 14 & - & - & - & - & $\mathrm{H}$ & 100 \\
\hline create sustainable communities & 10 & 7 & 6 & - & - & - & $\mathrm{H}$ & 100 \\
\hline has no advantages & - & 1 & - & 3 & 9 & 10 & $\mathrm{H}$ & 4 \\
\hline
\end{tabular}

Key: Consensus: $\mathrm{H}=$ High; $\mathrm{M}=$ Medium; $\mathrm{L}=$ Low; $\mathrm{N}=$ None.

Mode response is indicated in bold.

\% Positive includes responses to 'Strongly agree', 'Agree' and 'Somewhat agree'. 


\begin{tabular}{|c|c|c|c|c|c|c|c|c|}
\hline $\begin{array}{l}\text { Group self-build or custom } \\
\text { build is more likely to... }\end{array}$ & 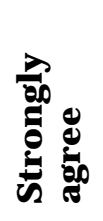 & $\begin{array}{l}8 \\
\text { \& }\end{array}$ & 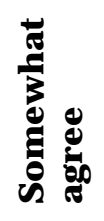 & 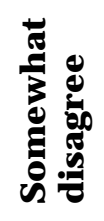 & 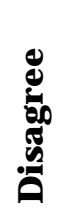 & 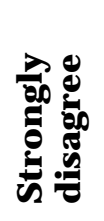 & 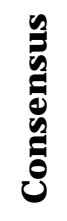 & 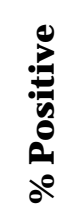 \\
\hline be energy efficient & 1 & 10 & 3 & 2 & - & - & $\mathrm{H}$ & 87 \\
\hline be affordable & 1 & 8 & 5 & 2 & - & - & $\mathrm{H}$ & 87 \\
\hline be innovative & 5 & 6 & 6 & - & - & - & $\mathrm{H}$ & 100 \\
\hline be of a higher quality & 2 & 6 & 6 & 1 & - & - & $\mathrm{H}$ & 93 \\
\hline meet the needs of the occupants & 7 & 9 & - & - & - & - & $\mathrm{H}$ & 100 \\
\hline create sustainable communities & 7 & 4 & 4 & 1 & - & - & $\mathrm{H}$ & 94 \\
\hline
\end{tabular}

Key: Consensus: $\mathrm{H}=$ High; $\mathrm{M}=$ Medium; $\mathrm{L}=$ Low; $\mathrm{N}=$ None.

Mode response is indicated in bold

\% Positive includes responses to 'Strongly agree', 'Agree' and 'Somewhat agree'.

4.3 Disadvantages of group self-build as a development model for zero carbon homes In Round 1, panellists were also asked to identify the disadvantages of group self-building as a development model for zero carbon homes. Six themes were identified: there are no disadvantages, difficult to finance, requires commitment, sites are difficult to obtain, zero carbon is too complex, and group issues (Table 8). The difficulty of securing finance and group issues were most frequently identified. In addition to the themes, a series of other disadvantages were also identified by individual panellists. These were typically in contrast with advantages previously identified - panellists had therefore been given the opportunity to disagree and comment should they wish. These issues included: ensuring quality control, more expensive, lack of skills, and cultural change required. 
Table 8: Disadvantages of group self-build as a development model for zero carbon homes

\begin{tabular}{ll}
\hline Theme & Specific disadvantages \\
\hline No disadvantages & There are challenges but no disadvantages \\
\hline Difficult to finance & Risk of innovative solutions \\
& Need for upfront capital \\
& Not suitable for the financially insecure \\
& Staged mortgages \\
\hline Requires commitment & Time consuming \\
& Requires buy-in from stakeholders \\
& Not conducive to heavy work or family commitments \\
\hline Sites are difficult to obtain & \\
\hline Zero carbon is too complex & Lack of information for groups of self-builders \\
& Legal complications of shared services and responsibilities \\
& (renewables) \\
& Eco-technology is complicated and unproven \\
\hline Group issues & Reaching consensus \\
& Finding people to collaborate with \\
& Different lifestyles \\
\hline
\end{tabular}

The statements developed in relation to the disadvantages of group self-build housing as a development model for zero carbon homes were the same for both the regional (Table 9) and national (Table 10) studies. For the statement 'Group self-build or custom build has no disadvantages', the majority of the regional panellists disagree to some extent, with the mode response being 'somewhat disagree'. A slightly higher proportion of panellists agree with this statement within the national study. Whilst both the regional and national panellists generally disagree with the statement that 'zero carbon is too complex for group self-build or custom build', there is less consensus on this in the national than the regional study. In the national study, the mode response was 'disagree', and the majority of respondents disagreed with the statement. However, responses were spread across all categories of agreement ('strongly agree' to 'strongly disagree'). In the regional study, the majority of respondents also disagreed with the statement, but the mode response was 'somewhat agree'. 


\begin{tabular}{|c|c|c|c|c|c|c|c|c|}
\hline $\begin{array}{l}\text { Group self-build or custom build } \\
\text { housing }\end{array}$ & 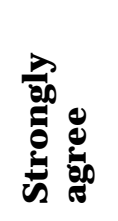 & 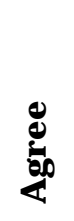 & 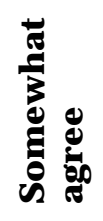 & 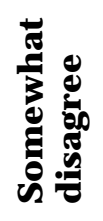 & 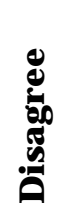 & 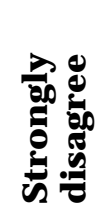 & 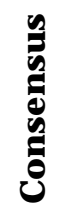 & 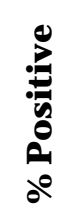 \\
\hline ...has no disadvantages & - & - & 5 & 11 & 5 & 2 & M & 22 \\
\hline ... requires commitment to the process & 11 & 10 & 2 & - & - & - & $\mathrm{H}$ & 100 \\
\hline .. is difficult to finance & 2 & 12 & 7 & 1 & 1 & - & $\mathrm{H}$ & 91 \\
\hline Zero carbon is too complex for... & 1 & - & 8 & 7 & 7 & - & M & 39 \\
\hline Finding sites is difficult for... & 9 & 10 & 4 & - & - & - & $\mathrm{H}$ & 100 \\
\hline
\end{tabular}

Key: Consensus: $\mathrm{H}=$ High; $\mathrm{M}=$ Medium; $\mathrm{L}=$ Low; $\mathrm{N}=$ None.

Mode response is indicated in bold

$\%$ Positive includes responses to 'Strongly agree', 'Agree' and 'Somewhat agree'.

Table 10: National study - Round 2 - Disadvantages of group self-build (counts)

\begin{tabular}{|c|c|c|c|c|c|c|c|c|}
\hline $\begin{array}{l}\text { Group self-build or custom build } \\
\text { housing }\end{array}$ & 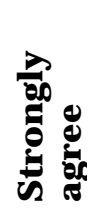 & $\begin{array}{l}\text { 巳 } \\
\text { क्ष }\end{array}$ & 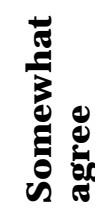 & 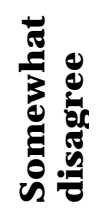 & 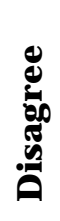 & 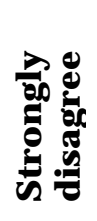 & 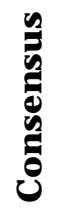 & 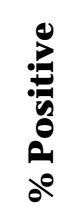 \\
\hline ... has no disadvantages & 1 & 2 & 2 & 3 & 7 & 2 & M & 29 \\
\hline ... requires commitment to the process & 11 & 5 & 1 & - & - & - & $\mathrm{H}$ & 100 \\
\hline ... is difficult to finance & 3 & 8 & 6 & - & - & - & $\mathrm{H}$ & 100 \\
\hline Zero carbon is too complex for... & 1 & 1 & 4 & 3 & 7 & 1 & $\mathrm{~L}$ & 35 \\
\hline Finding sites is difficult for... & 9 & 6 & 2 & - & - & - & $\mathrm{H}$ & 100 \\
\hline
\end{tabular}

Key: Consensus: $\mathrm{H}=$ High; $\mathrm{M}=$ Medium; $\mathrm{L}=$ Low; $\mathrm{N}=$ None.

Mode response is indicated in bold

$\%$ Positive includes responses to 'Strongly agree', 'Agree' and 'Somewhat agree'.

\section{Discussion}

The findings presented in Section 3 stem from the two initial questions posed to panellists What are the advantages of group self-build housing as a development model for zero carbon homes?' and 'What are the disadvantages of group self-build housing as a development model for zero carbon homes?'. The responses summarised in Table 3 highlight a diverse range of advantages which are grouped into the themes: energy efficiency, affordability, quality, innovation, sustainable communities, and meeting the needs of occupants. Whilst some of these themes may seem less directly related to the achievement of zero carbon homes, from the perspective of the panellists, these are the potential advantages they perceive as a result of group self-build models of procurement. It is possible that panellists have responded more 
broadly because the questions were asked in the context of an introduction to participants which established a research interest in sustainable communities in addition to group selfbuild housing and zero carbon homes. But the findings highlight that the panellists conceive zero carbon homes as a more broadly interrelated concept, rather than simply a technical standard. Indeed, Goodchild and Walshaw (2011) describe zero carbon homes as a form of socio-technical system - an interconnected network of social organisations and physical technologies (Lovell, 2007) - and it is believed that the responses illustrate the perceived complexity of this system.

The key findings are now discussed in the context of the literature, with contrasting participant views presented. Quotes from panellists are included to support the discussion.

\subsection{Energy efficiency}

As established in Section 1, building fabric energy efficiency, on-site energy generation using low and zero carbon technologies and carbon offsetting are the three elements of the zero carbon homes standard. All panellists in the regional study, and the significant majority in the national study, believed that self-build homes are more likely to be energy efficient than speculatively built homes. Whilst this supports the assertions within the literature that, due to having a long-term investment in a home and interests in its running costs, self-builders are more likely to invest in energy efficiency measures (Brown et al., 2013; DCLG, 2011; NaSBA, 2011; Parvin et al., 2011), the reasons cited within this study went beyond the focus on the running cost of a home to identify additional advantages which support the delivery of zero carbon homes.

Panellists suggested that occupants would have a better understanding of the home energy system and as such would be able to operate it more efficiently: The occupier has an understanding on how the building is designed and constructed and how it can be best operated to optimise its low energy credentials' [Public Sector, Regional study]. Notably, this would address a previously identified barrier to the delivery of zero carbon homes - lack of occupant knowledge on a home's efficient operation (Heffernan et al., 2015; Osmani and O’Reilly, 2009). Panellists also stated that, by working as a group, self-builders could invest in shared energy systems which could offer efficiencies: 'Ability to pool resources for low carbon fuel sources which are generally more efficient and cheaper the larger they get, e.g. wood pellet/ biomass boilers, CHP units, solar installations, ground source heat via small scale district heating etc.' [Public Sector, Regional study]. Lancaster Cohousing offers one such example (Self Build Portal, 2014), in which the community shares photovoltaic and hydroelectric systems for electricity and a biomass boiler and solar thermal system for heat. The combination of very high levels of energy efficiency due to the homes being built to Passivhaus standard and shared low and zero carbon energy systems have resulted in the 
creation of a zero carbon group self-build community. However, Regional panellist cautioned that:

Unless the self-builder really understands the issues, it is all too easy to get side tracked into installing a load of Eco Bling that mean you may have built a poor house but loads of add-ons to make it zero carbon.' [Expert, Regional study]

The panel were able to identify two further benefits of self-build which had not previously been identified within the literature: the ability for self-builders to share information about and raise awareness of zero carbon, and stimulate demand for zero carbon. Importantly, both of these benefits could serve to address further barriers to zero carbon homebuilding (Heffernan et al., 2015; Osmani and O’Reilly, 2009); specifically, lack of demand for zero carbon homes and lack of awareness regarding the zero carbon homes standard. Panellists stated that group self-build participants would become 'zero carbon advocates' within their wider communities.

\subsection{Sustainable communities}

All panellists in the regional study, and the majority in the national study, believed that selfbuild homes are more likely to create sustainable communities than speculatively built housing.

Panellists suggested self-build homes are more likely to create sustainable communities because self-builders are typically interested in sustainable lifestyle choices, thus goingbeyond the impact of the home as a technical system and considering the holistic impact of the way they live: 'Occupants will live the dream of a Zero Carbon Homein its broadest sense' [Expert, National study] and 'Supports new communities to adapt their lifestyles to live more sustainable lives' [Housing Association, Regional study]. These quotes illustrate that panellists are considering the impact the technical system of the home will have on the social network to which it is connected.

Panellists suggested that the act of building, designing, planning or procuring as a group in itself creates bonds within a community: 'Group self-build can potentially lead to more connected/ resilient communities' [Expert, National study] and 'Opportunity to forgestronger links with neighbours \& local residents' [Housing Association, National study]. The idea that the community network formed through a group self-build can often result in deeper engagement with the governance of the community was supported by panellist responses (Mullins, 2018; Parvin et al., 2011). It has been suggested that the benefits of community interaction tend to go beyond the group self-build development and spread to the wider neighbourhood community (Broer and Titheridge, 2010; Brown et al., 2013).

The panellists suggested that the potential for empowerment of the individual, the group and the local community as a result of the skills and confidence gained through the self-build 
process, is another reason that group self-build housing creates sustainable communities: Builds skills and confidence - great for everyone especially young people or those who are rebuilding their lives e.g. ex offenders, ex military' [Expert, Regional study] and 'fun, selffulfilment, satisfaction' [Expert, National study].

Two further benefits of group self-build in terms of its likelihood to help create sustainable communities were identified: facilitating local people to provide homes for themselves within their own community, and greater design variety, with a suggestion this would create more interesting places - speculative housebuilding in the UK having been noted for its 'homogeneity' (Lloyd et al., 2015).

One Expert in the National study raised a note of caution over the potential self-selectivity of group self-builders, leading to a narrow demographic within the group and questionable social sustainability:

'On the issue of sustainability, the environmental credentials can be good particularly where low car use is encouraged, but residential self-selectivity can lead to narrow demographic profiling of residents - e.g. by age, income, background etc. which can make the social sustainability credentials questionable' [Expert, National study].

However, this has to be tempered against the other social sustainability benefits, such as empowerment, discussed here and the views from the literature which suggest that group selfbuild, in particular, lowers the threshold for entry to the self-build market and indeed home ownership (Heffernan and de Wilde, 2017; Parvin et al., 2011).

Another counter-argument on the broader impact of the perceived density of self-build housing on the creation of sustainable communities emerged: There is little point in creating zero or very low carbon housing if it requires private transport and large areas of land' [Designer, National study]. However, many of the group self-build models from mainland Europe and the cohousing developments in the UK hold higher density and reduced reliance on private transport as essential features (Chatterton, 2013; Hamiduddin and Gallent, 2016).

\subsection{Affordability}

The majority of panellists in both studies believed that, in the context of zero carbon homebuilding, group self-build homes are more likely to be affordable than speculatively built homes. The primary reasons cited for this by the panellists were that groups can benefit from economies of scale in the procurement of goods and services and the purchase of land, and that by undertaking elements of the work themselves they could make additional savings. In terms of economies of scale, panellists again referred to shared energy systems, and also linked this concept to practices of collaborative consumption (Huber, 2017) such as car sharing, food growing and bartering of skills. Once again, this broader view taken by the research 
participants connects the technical systems of a zero carbon home or group self-build community with the social networks within which they operate.

Panellists suggested that zero carbon homes are not financially viable for speculative developers but are more feasible through group self-build models: Zero carbon homes arenot economically viable for mainstream developers as the additional costs involved in their construction are not reflected in the valuation at the end of the build...Therefore, self-build is likely to be one of the only ways of building zero carbon homes' [Housing Association, National study]. This quote evidences a perception that the delivery of zero carbon homes is to some extent reliant on self-build models of procurement.

Affordability in operation was a recurrent themein Round 1responses from panellists, relating to the improved energy efficiency of self-build homes, with the benefit of ongoing reduced running costs.

Whilst the identification of improved affordability as an advantage of group self-build housing aligns with the existing literature (Brown et al., 2013; Dol et al., 2012; Falk and Carley, 2012; Heffernan and de Wilde, 2017; Miles and Whitehouse, 2013), this research has uncovered many ways in which affordability is enhanced in the context of group self-building zero carbon homes.

\subsection{Quality}

Although the concept of improved quality in self-build homes is not new (Miles and Whitehouse, 2013; RIBA, 2009) previous research has linked this quality only to 'cost and performance in use and build quality' (Miles and Whitehouse, 2013, p. 19) and not with a specific focus on energy efficiency or zero carbon homes. In the context of zero carbon homes, the majority of panellists believe that group self-build would typically deliver homes of a higher quality than those delivered by speculative developers: 'Self-builders have a vested interest in the quality and effectiveness of the buildings' [Designer, Regional study]. The following quote from a financial institution representative suggests a focus on indoor environmental quality, necessary for an effective and efficient zero carbon home, is possible through group self-build: '. . air quality, healthy homes and comfort - all desirable results for a self-builder, not necessarily prevalent in mass produced housing' [Financial Institution, National study]. However, notes of caution were raised by some panellists regarding a potential lack of ability amongst inexperienced self-builders: 'Some building technologies do need high quality building skills to achieve (e.g. air-tightness) - not sure if all self-builders are up to it?!' [Designer, Regional study]. The findings therefore suggest a likely aspiration for high quality construction amongst group self-builders constructing zero carbon homes, but also a potential lack of experience or ability. 


\subsection{Innovation}

All panellists in the national study, and the majority in the regional study, believed that group self-build housing, as a development model for zero carbon homes, is more likely to be innovative than speculatively built housing: "[Self-build groups] can do things a larger scale developer wouldn't be interested in due to scale/ efficiency (e.g. incorporate untested/experimental technology)' [Public Sector, Regional study] and '[Group selfbuilding] allows for pioneering approaches and a learning process' [Public Sector, National study]. Reasons cited for this by the panellists were that self-builders are more open to experimenting because they are less risk averse than speculative builders and they work on a smaller scale at which the consequences of failure would be limited. The literature further suggests that the use of innovation within the self-build sector can stimulate the adoption of these innovations in mainstream housebuilding (Barlow et al., 2001; Falk and Carley, 2012). Therefore, group self-build may have the potential to support the transition of zero carbon design and construction from niche to mainstream.

\subsection{Collective advantages}

In the preceding sub-sections, the themes of advantages have been discussed, and it has been highlighted that the Policy Delphi panellists were able to identify a number of advantages which had not previously been apparent within the literature. Thus, whilst the themes of advantages identified in this research are largely supportive of the literature, greater depth and nuances within these themes have emerged. What has also become apparent, is the interconnected nature of the advantages of group self-build as a development model for zero carbon homes. The potential for group self-builders to become zero carbon advocates, who raise awareness of and stimulate demand for zero carbon, provides support for the claim that group self-build can help to transition zero carbon from niche to mainstream. This role of awareness raising is also enhanced and extended by people in these communities living more sustainable lives in holistic terms. Which, in turn, also connects with the broad opportunities for collaborative consumption identified under the theme of affordability. A belief in the intrinsic link between achieving zero carbon and the need for high quality construction is evident amongst the responses of panellists. And whilst it was not universal, there was a belief that group self-build homes are likely to offer both greater variety in design and quality in construction, enhancing the richness and quality of built communities.

\subsection{Disadvantages}

From the Round 1 qualitative data, five themes of disadvantages of group self-build housing as a development model for zero carbon homes were identified. Through the Round 2 questionnaire, the panel supported only three of the statements: Group self-build or custom build housing is difficult to finance, Group self-build or custom build housing requires 
commitment, and Finding sites is difficult for group self-build or custom build housing. Increased activity in independent, supported and developer led group self-build projects (e.g. Broadhempston Community Land Trust, n.d.; Chatterton, 2013; Trivselhus, 2019) is indicative of the fact that groups can find sites, acquire finance, and form a committed unit to take projects forward (Heffernan and de Wilde, 2017; Wainwright, 2013). The three perceived disadvantages - difficulty of obtaining finance and acquiring sites and the requirement for commitment to the process - relate very strongly to the group self-build model of procurement, rather than specifically to the added overlay of meeting the zero carbon homes standard. In the context of self-build housing in the UK, all of these disadvantages have been identified and discussed within the literature previously (Barlow et al., 2001; Mullins and Moore, 2018; Parvin et al., 2011; Wallace et al., 2013), and policy mechanisms have been leveraged to attempt to address the disadvantages relating to finance and acquiring sites (Aspinall Verdi, 2016). For example, Local Planning Authorities are now required to maintain a register of individuals and groups who are interested in acquiring a serviced plot for self-building (HM Government, 2016), and self-build homes are exempt from the Community Infrastructure Levy (planning contributions) (HM Government, 2019). However, enabling funds targeted specifically at group self-build were introduced only for a brief time (Homes and Communities Agency, 2012).

Of more interest and relevance to the research aim, is to consider further the two statements relating to disadvantages which were not supported by the participants, and thus it is concluded are not valid statements: 'Group self-build or custom build housing has no disadvantages as a development model for zero carbon homes' and 'Zero carbon is too complex for group self-build or custom build housing. For both of these proposed disadvantages (which relate very specifically to the suitability of group self-build as a development model for zero carbon homes), whilst the majority of the participants in both the regional and national panels disagreed with the statements to some extent, lower levels of consensus were achieved.

The responses in Round 1, from which the statement 'zero carbon is too complex...' was developed, refer to the complexity of the zero carbon homes standards for construction industry professionals:

'...the construction of zero carbon homes is too difficult technically for the most advanced minds in the country, even Bill Dunster can't necessarily get the team around him that he needs because everyone else is so far behind... So how could self-builders cope?' [Housing Association representative, Regional study].

Zero carbon homes are a highly technical product that must meet stringent standards in terms of build quality and air tightness...Currently in the UK these homes are rarely built by construction companies to actually meet the high performance standards that they have been designed to meet...This problem will be exacerbated in a situation where the construction team includes 
members who are untrained and unused to the construction industry.'

[Designer, National study].

These quotes therefore suggest that some panellists believe that the zero carbon homes standard is complex for trained professionals, and would likely be even more so for selfbuilders. The polar opinions relating to this statement were observed between the above quoted Housing Association representative in the regional study and Contractor in the national study (strongly agree) compared with an expert in the national study (strongly disagree). There were no notable patterns of response from particular panellist categories. It is therefore believed that responses relatemore strongly to personal experienceand familiarity with the zero carbon homes standard than to the professional group in which they operate.

The second unsupported statement 'Group self-build or custom build housing has no disadvantages as a development model for zero carbon homes' was developed from the following response:

I do not consider that the group 'self build' route has cons [disadvantages] that are intrinsic to it being a development model. The following 'cons' relate to potential limits to the expertise or abilities of self build groups...' [Expert, National study]

This quote suggests that the variable backgrounds, skills and knowledge of group members has the potential to bring disadvantages to a group, but that the route itself is not intrinsically flawed for the provision of zero carbon homes. Whilst some panellists in both the national and regional studies agreed with this statement (to varying degrees), the majority disagreed. This reflects that there is agreement that group self-build housing cannot be seen as a panacea for the problems of housing supply in the UK. The extreme responses were observed amongst an Expert in the national study (strongly agree) and an Expert and Designer in the national study and Public Sector and Housing Association representatives from the regional study (strongly disagree).

These findings - that the majority believe that the zero carbon homes standard is not too complex for group self-build homes, but also that there are disadvantages in group self-build housing as a development model for zero carbon homes - are of relevance in satisfying the research aim. It is unsurprising that socio-technical systems as complex as group self-build housing and zero carbon homes will have disadvantages. However, within this study, the panellists were able to identify many more advantages than disadvantages for group self-build housing as a development model for zero carbon homes. Similarly, the study conducted by Wallace et al. (2013) identified more strengths than weaknesses of the self-build sector. Tummers (2016) suggests that much of the group self-build literature remains focused on 
advocacy for the sector. As a result, the majority of the literature on self-build housing is overwhelmingly supportive of these forms of development.

\section{Conclusion}

The Policy Delphi method was employed for this research exploring expert perceptions regarding the suitability of group self-build as a development model for zero carbon homes in the UK. This paper has both identified and extended a number of themes of advantages and disadvantages for group self-build as a development model for zero carbon homes. The advantages identified by the panel were grouped under the themes of: energy efficiency, affordability, quality, innovation, sustainable communities, and meeting the needs of occupants. Responses provided evidence of panellists considering the impact of the technical system of the home on the social network within which it exists. The interconnected nature of the advantages of group self-build as a development model for zero carbon homes was highlighted. A role for group self-builders as zero carbon advocates, who raise awareness of and stimulate demand for zero carbon homes, was identified, supporting an assertion that group self-build can help to transition zero carbon from niche to mainstream. Despite five themes of disadvantages being identified in Round 1 of the Policy Delphi, the panel supported only three of the themes: difficulty of financing, requirement for commitment, and difficulty of obtaining sites. In the discussion of this paper it was argued that these disadvantages are common to group self-build as a model, and are not directly related to the potential of achieving zero carbon. Whilst there was relatively low consensus in comparison to the other disadvantages - and the responses highlighted some perceptions that the zero carbon homes standard was too complex for construction professionals, and thus potentially to a greater extent for self-builders - the majority in both the regional and national studies disagreed with the statement 'Zero carbon is too complex for group self-build or custom build housing'. Indeed, some panellists suggested that self-build is one of the only ways in which zero carbon homes can be delivered.

Group self-build housing is a small but believed to be growing contributor to the UK housebuilding sector. This paper has found that, in the opinions of experts, models of group self-build housing have the potential to support a more environmentally and socially sustainable built environment in which homes are energy efficient, people are empowered, and zero carbon homes are facilitated. Given the significance of these advantages, the findings of this paper ratify the policy support provided to the group self-build housing sector by the UK government. Policy which supports all three routes to group self-build housing should be maintained and developed centrally, and encouraged at the local government level. Policy interventions should seek to address the barriers of finance, land acquisition and skills and knowledge development of groups. Specifically, a reintroduction of interim enabling funds for 
group self-build projects, to help groups navigate the often prohibitive land purchase and planning stages of development, would help to continue to stimulate growth in the sector. Furthermore, given the potential for self-build groups to act as advocates for zero carbon homebuilding, policy in which a platform for this advocacy is provided could enable awareness-raising of both group self-build and zero carbon homes, and encourage further grass roots activity in the delivery of sustainable housing and communities. This grass roots action will make an important contribution to the movement towards a low carbon built environment in the UK in the absence of mandatory requirements to do so.

\section{Acknowledgements}

The authors would like to thank the research participants for their time and insights, and Cornwall Council and Cornwall Sustainable Buildings Trust for their support for the research project.

Funding: This work was supported by the European Social Fund through the Combined Universities in Cornwall [ESF project number 11200NC05]. The funding body had no involvement in the study design; the collection, analysis and interpretation of data; or the decision to submit this article for publication. This paper was written with the support of the ARC Research Hub for Australian Steel Manufacturing [ARC grant number IH130100017].

\section{References}

Aspinall Verdi, 2016. Planning for Self-Build and Custom Housebuilding. Leeds.

Bailey, R., Longhurst, J.W.S., Hayes, E.T., Hudson, L., Ragnarsdottir, K.V., Thumim, J ., 2012. Exploring a city's potential low carbon futures using Delphi methods: some preliminary $\begin{array}{llll}\text { findings. } & \text { J . Pnviron. } & \text { 37-41. }\end{array}$ https:// doi.org/ 10.1080/09640568.2011.635192

Barker, K., 2004. Review of Housing Supply, Delivering Stability: Securing our Future Housing Needs. Norwich.

Barlow, J., Meikle, J.., Jackson, R., 2001. Homes to DIY for: the UK's self-build housing market in the twenty-first century.

Benson, M., 2014. Creating a nation of selfbuilders. London.

Benson, M., Hamiduddin, I., 2017. Self-build homes: social values and the lived experience of housing in practice, in: Benson, M., Hamiduddin, I. (Eds.), Self-Build Homes: Social Discourse, Experiences and Directions. UCL Press, London, pp. 1- 14.

Boonstra, B., Boelens, L., 2011. Self-organization in urban development: Towards a new perspective on spatial planning. Urban Res. Pract. 4, 99- 122. https:/ / doi.org/ 10.1080/17535069.2011.579767

Broadhempston Community Land Trust, n.d. Broadhempston Community Land Trust [WWW Document]. URL https:// broadhempstonclt.com/ (accessed 6.20.19). 
Broer, S., Titheridge, H., 2010. Eco-self-build housing communities: Are they feasible and can they lead to sustainable and low carbon lifestyles? Sustainability 2, 2084-2116. https:// doi.org/ 10.3390/ su2072084

Brown, S., Cerulli, C., Stevenson, F., Ash, C., Birkbeck, D., 2013. Motivating Collective Custom Build. Sheffield.

Chatterton, P., 2013. Towards an agenda for post-carbon cities: Lessons from lilac, the uk's first ecological, affordable cohousing community. Int. J . Urban Reg. Res. 37, 1654- 1674. https:/ / doi.org/ 10.1111/ 1468-2427.12009

Clegg, F., 1997. Simple Statistics: A course book for the social sciences. University Press, Cambridge.

Cohen, L., Manion, L., Morrison, K., 2011. Research methods in education, 7th end. ed. Routledge, Abingdon, UK.

Collins, K., 2017. Building a self: community self-build and the reconstruction of identity, in: Benson, M., Hamiduddin, I. (Eds.), Self-Build Homes: Social Discourse, Experiences and Directions. UCL Press, London, pp. 192- 206.

Creswell, J.W., 2014. Research Design: Qualitative, Quantitative \& Mixed Methods Approaches, 4th edn. ed. SAGE Publications, London.

DCLG, 2017. Fixing our broken housing market, Housing White Paper. London. https:// doi.org/ https:// www.gov.uk/ government/ uploads/system/ uploads/ attachment _data/file/ 590463/ Fixing_our_broken_housing_market_-_accessible_version.pdf

DCLG, 2011. Laying the Foundations: A Housing Strategy for England, Department for Communities and Local Government (DCLG). London.

DCLG, 2007. Building a Greener Future: policy statement. London.

deLoe, R.C., 1995. Exploring complex policy questions using the policy Delphi. A multi-round, interactive survey method. Appl. Geogr. 15, 53-68. https://doi.org/ 10.1016/01436228(95)91062-3

Department for Business Energy \& Industrial Strategy, 2019. Energy Consumption in the UK (ECUK): Final Energy Consumption Tables. London.

Dol, K., Lennartz, C., De Decker, P., 2012. Self-provided housing in developed societies, in: Smith, S. (Ed.), International Encyclopaedia of Housing and Home. Elsevier, Oxford, pp. 310- 315 .

Duncan, S.S., Rowe, A., 1993. Self-provided Housing: The First World's Hidden Housing Arm. Urban Stud. 30, 1331- 1354. https:/ / doi.org/ 10.1080/ 00420989320081291

Falk, N., Carley, M., 2012. Sustainable urban neighbourhoods: Building communities that last. York.

Fernández-Viñé, M.B., Gómez-Navarro, T., Capuz-Rizo, S.F., 2013. Assessment of the public administration tools for the improvement of the eco-efficiency of Small and Medium Sized Enterprises. J. Clean. Prod. 47, 265-273. https:// doi.org/ 10.1016/j.jclepro.2012.08.026

Goodchild, B., Walshaw, A., 2011. Towards Zero Carbon Homes in England? From Inception to Partial Implementation. Hous. Stud. 26, 933-949. https:// doi.org/ 10.1080/02673037.2011.593132

Gram-Hanssen, K., 2011. Households' Energy Use - Which is the More Important: Efficient Technologies or User Practices?, in: Proceedings of the World Renewable Energy 
Congress - Sweden, 8-13 May. Linköping, Sweden, pp. 992-999. https:/ / doi.org/ 10.3384/ ecp11057992

Greenwood, D., Congreve, A., King, M., 2017. Streamlining or watering down? Assessing the "smartness" of policy and standards for the promotion of low and zero carbon homes in England 2010-15. Energy Policy 110, 490-499. https:// doi.org/ 10.1016/j.enpol.2017.08.033

Hahn, E.J ., Rayens, M.K., 1999. Consensus for tobacco policy among former state legislators using the policy Delphi method. Tob. Control 8, 137- 140. https:// doi.org/ 10.1136/tc.8.2.137

Hamiduddin, I., Gallent, N., 2016. Self-build communities: the rationale and experiences of group-build (Baugruppen) housing development in Germany. Hous. Stud. 31, 365- 383. https:/ / doi.org/ 10.1080/02673037.2015.1091920

HBF, 2012. South West: Housing crisis report. London.

Heffernan, E., de Wilde, P., 2017. Something wonderful in my back yard: the social impetus for group self-building, in: Benson, M., Hamiduddin, I. (Eds.), Self-Build Homes: Social Discourse, Experiences and Directions. UCL Press, London, pp. 174- 191.

Heffernan, E., Pan, W., Liang, X., de Wilde, P., 2015. Zero carbon homes: Perceptions from the UK construction industry. Energy Policy 79, 23-36. https:/ / doi.org/ 10.1016/j.enpol.2015.01.005

Heffernan, E.E., 2015. Delivering zero carbon homes and sustainable communities: The potential of group self-build housing in England. University of Plymouth.

HM Government, 2019. The Community Infrastructure Levy (Amendment) (England) (No. 2) Regulations 2019. England.

HM Government, 2016. The Self-build and Custom Housebuilding (Register) Regulations 2016. England.

HM Government, 2010. Building and Buildings, England and Wales- The Building Regulations 2010. UK.

HM Government, 2008. Climate Change Act 2008: Elizabeth II. Chapter 27. London, Great Britain.

Homes and Communities Agency, 2012. Custom Build Homes Loan Fund: prospectus [WWW Document]. URL https:// www.gov.uk/ government/publications/custom-build-homesloan-fund-prospectus (accessed 9.11.19).

Huber, A., 2017. Theorising the dynamics of collaborative consumption practices: A comparison of peer-to-peer accommodation and cohousing. Environ. Innov. Soc. Transitions 23, 53- 69. https:/ / doi.org/ 10.1016/j.eist.2016.12.001

J efferys, P., Lloyd, T., Argyle, A., Sarling, J ., Crosby, J ., Bibby, J ., 2014. Building the homes we need: A program for the 2015 Government. London.

Keeney, S., Felicity, H., Hugh, M., 2006. Consulting the oracle: ten lessons from using the Delphi technique in nursing research. J. Adv. Nurs. 53, 205-212. https:// doi.org/ 10.1111/j.1365-2648.2006.03716.x

Landeta, J., Barrutia, J., 2011. People consultation to construct the future: A Delphi $\begin{array}{lllll}\text { application. Int. } & \text { Forecast. }\end{array}$ https:// doi.org/ 10.1016/j.jjforecast.2010.04.001

Lloyd, M.G., Peel, D., Janssen-J ansen, L.B., 2015. Self-build in the UK and Netherlands: 
mainstreaming self-development to address housing shortages? Urban, Plan. Transp. Res. 3, 19-31. https:// doi.org/ 10.1080/21650020.2014.987403

Lovell, H., 2007. The governance of innovation in socio-technical systems: The difficulties of strategic niche management in practice. Sci. Public Policy 34, 35-44. https:/ / doi.org/ 10.3152/030234207X190540

Lovell, H., Corbett, J ., 2018. What Makes a Zero Carbon Home Zero Carbon?, in: Rhodes, R.A.W. (Ed.), Narrative Policy Analysis: Cases in Decentred Policy. Palgrave Macmillan, London, pp. 47- 70. https:// doi.org/ doi.org/10.1007/978-3-319-76635-5_3

Marckmann, B., Gram-Hanssen, K., Christensen, T.H., 2012. Sustainable living and cohousing: Evidence from a case study of eco-villages. Built Environ. 38, 413-429. https:// doi.org/ 10.2148/ benv.38.3.413

Miles, J., Whitehouse, N., 2013. Offsite Housing Review, Department of Business, Innovation \& Skills and the .... London: Construction Industry Council.

Mullins, D., 2018. Achieving policy recognition for community-based housing solutions: the case of self-help housing in England. Int. J. Hous. Policy 18, 143- 155. https:// doi.org/ 10.1080/ 19491247.2017.1384692

Mullins, D., Moore, T., 2018. Self-organised and civil society participation in housing provision. Int. Hous. Policy 18, 1- 14 . https:/ / doi.org/ 10.1080/ 19491247.2018.1422320

NaCSBA, 2019. Self Build Portal [WWW Document]. URL www.selfbuildportal.org.uk/ (accessed 6.11.19).

NaCSBA, 2018. Routes to building your own home [WWW Document]. Self Build Portal. URL https:// www.selfbuildportal.org.uk/ (accessed 8.16.18).

Narara Ecovillage, 2019. Discover Sustainable Community on the Central Coast [WWW Document]. URL https:// nararaecovillage.com/ (accessed 6.20.19).

NaSBA, 2011. An Action Plan of self build housing, NaSBA. Swindon.

National Community Land Trust Network, 2019. Find a CLT [WWW Document]. URL http:// www.communitylandtrusts.org.uk/ what-is-a-clt/ find-a-clt (accessed 9.9.19).

O'Loughlin, R., Kelly, A., 2004. Equity in resource allocation in the Irish health service: A policy Delphi study. Health Policy (New. York). 67, 271- 280. https:// doi.org/ 10.1016/j.healthpol.2003.07.001

Osmani, M., O’Reilly, A., 2009. Feasibility of zero carbon homes in England by 2016: A house builder's perspective. Build. Environ. 44, 1917- 1924. https:// doi.org/ 10.1016/j.buildenv.2009.01.005

Palmer, J.S., 2019. Collective self-organised housing, an opportunity for consolidating the Australian dream. Aust. Plan. https:/ / doi.org/ 10.1080/07293682.2019.1595690

Paraskevas, A., Saunders, M.N.K., 2012. Beyond consensus: An alternative use of Delphi enquiry in hospitality research. Int. J. Contemp. Hosp. Manag. 24, 907-924. https:// doi.org/ 10.1108/ 09596111211247236

Parvin, A., Saxby, D., Cerulli, C., Schneider, T., 2011. A right to build: The next masshousebuilding industry. Sheffield.

PfP igloo, n.d. Living at Heartlands [WWW Document]. URL https:// www.homemadeheartlands.co.uk/ live-at-heartlands (accessed 6.20.19). 
Picavet, E., Cassiman, D., Simoens, S., 2012. Evaluating and improving orphan drug regulations in Europe: A Delphi policy study. Health Policy (New. York). 108, 1-9. https:// doi.org/ 10.1016/j.healthpol.2012.08.023

QSR International, 2019. NVivo [WWW Document]. URL www.qsrinternational.com/ nvivo/ what-is-nvivo (accessed 6.1.19).

Qualtrics, 2019. Qualtrics [WWW Document]. URL www.qualtrics.com (accessed 6.1.19).

Rayens, M.K., Hahn, E.J ., 2000. Building Consensus Using the Policy Delphi Method. Policy, Polit. Nurs. Pract. 1, 308-315. https://doi.org/ 10.1177/ 152715440000100409

RIBA, 2009. Improving Housing Quality: Unlocking the Market, RIBA. London.

Rubin, H.J., Rubin, I.S., 2005. Qualitative interviewing: the art of hearing data, 2nd edn. ed. SAGE, Thousand Oaks, CA.

Self Build Portal, 2014. Lancaster Cohousing [WWW Document]. URL https:// www.selfbuildportal.org.uk/ lancaster-co-housing-project (accessed 7.6.18).

Springhill Cohousing, 2017. Springhill Cohousing [WWW Document]. URL http://www.therightplace.net/ coco/ public/ (accessed 9.9.19).

Tracy, S.J., 2013. Qualitative Research Methods: Collecting evidence, crafting analysis, communicating impact. Wiley-Blackwell, Oxford.

Trivselhus, 2019. Marmalade Lane: Building a shared future [WWW Document]. URL https:// marmaladelane.co.uk/ (accessed 6.20.19).

Tummers, L., 2016. There-emergence of self-managed co-housing in Europe: A critical review of co-housing research. Urban Stud. 53, 2023-2040. https:// doi.org/ 10.1177/ 0042098015586696

Turoff, M., 2002. The Policy Delphi, in: Linstone, H.A., Turoff, M. (Eds.), The Delphi Method: Techniques and Applications. pp. 80-96.

Wainwright, O., 2013. The future's communal: meet the UK's self-build pioneers [WWW Document]. Guard. URL https:/ / www.theguardian.com/ artanddesign/ 2013/ may/ 07/ uk-self-build-pioneers

Wallace, A., Ford, J ., Quilgars, D., 2013. Understanding the changinglandscape of the UK selfbuild market. Spring.

Wheat, S., 2001. A home of one's own. Geographical 84- 89.

Wilson, W., 2017. Self-build and custom build housing (England), House of Commons Publication Library. London.

Wilson, W., Barton, C., 2018. Tackling the under-supply of housing in England, House of Commons Publication Library. London.

Wright, T.S.A., 2006. Giving "teeth" to an environmental policy: a Delphi Study at Dalhousie University. J . Clean. Prod. 14, 761- 768. https:// doi.org/ 10.1016/j.jclepro.2005.12.007

Zero Carbon Hub, 2014. Zero carbon homes and nearly zero energy buildings: UK Building Regulations and EU Directives. Milton Keynes. 